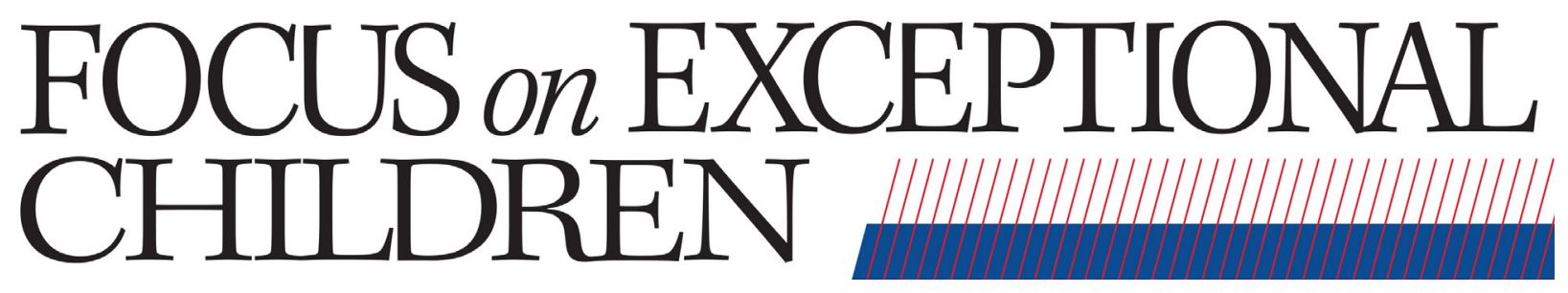

VOLUME 46 NUMBER 1 AUGUST 2019

\title{
The Future of "Disability:" The Evolution of the Concept and the Experience
}

\author{
Meyen Lecture \\ University of Kansas \\ March 28, 2018
}

\section{Philip M. Ferguson, Professor Emeritus, Chapman University*}

According to accounts (Davis, 2015; Pelka, 2012), July 26, 1990 was a bright and sunny day in Washington, DC. It was a perfect day to have a party and that was what 3000 members of the disability community did on the South Lawn of the White House. In the culmination of a years-long struggle, much of it kept as quiet as possible by disability activists (Davis, 2015), President George H. W. Bush signed into law the Americans with Disabilities Act. To an extent that seems unimaginable in today's political climate, the bill had passed through the Congress with an amazing degree of bipartisan support. ${ }^{1}$

Like many civil rights laws, the ADA has not lived up to its promise, and its promise was modest to start. There has certainly been progress. Words like "accessibility" and "reasonable accommodation" have become part of the daily rhetoric of disability rights. We expect to see the blue signs marking the accessible parking spaces. I would argue that the visibility of the disability community is noticeably greater than it was in 1990 . However, prospects for the deeper structural changes that would systemically alter the social inequality and marginalization of disabled people ${ }^{2}$ seem to be slipping further from view, not gaining the clarity that comes with closeness. The unemployment rate for people with disabilities remains depressingly high (Bureau of Labor Statistics, 2017). ${ }^{3}$ The courts have consistently taken a narrow view of who is covered by the law (Bagenstos, 2012; Emens, 2013). There are ongoing efforts to increase the burden of proof of discrimination carried by the victim rather than the offender. Even though the ADA Amendments Act of 2008 tried to repair some of the damage that court decisions had done in narrowing the coverage of the law, it created further potential problems in other ways (Emens, 2013). As a country we have not even joined 175 other countries and member organizations in ratifying the United Nations Convention on the Rights of People with Disabilities, which is, in many ways based on provisions found in the ADA itself. The goals of ADA remain largely unmet.

What I want to focus on about that day and the enactment of the ADA, is what it symbolizes for the disability rights movement, and by extension the academic cousin of that movement, the interdisciplinary field of disability studies. Almost all of the subsequent litigation following the passage of the ADA has focused on the definition of who, exactly, is to count as "disabled" under the law. The law itself, gave a three-part definition: A disabled person was any one who (1) has a substantial impairment that limited one or more life activities: (2) has had a history of such; or (3) is regarded as having such an impairment. The language of the definition was not new to the ADA; it came straight from Section 504 of the Rehabilitation Act which in many ways laid the foundation for the ADA. However, for our purposes, the ADA language is where I want to focus. More specifically, I want to focus on the third part of that definition. Taken in its most straightforward meaning, that third prong of the definition seems to endorse a social model of disability. It seems to allow for the possibility that disability can be a social construction. In political terms, the language was simply a recognition that someone could experience disability discrimination whether or not they were really disabled. Indeed, it seems to put disability itself in quotation marks: "Disability" as a concept rather than disability as a physical reality.

\footnotetext{
*Dr. Ferguson's research focuses on family/professional interactions, social policy and the history of intellectual disability.
} 
The point is not that this prong of the ADA definition has been applied much in practice. It has not. Almost all of the litigation and debate has been around the application of the first prong and the meaning of "substantial impairment" (Bagenstos, 2012). However, I want to use that third prong as a symbolic marker for the influence of disability studies in changing how we have come to talk and think about both the concept and experience of disability. As a concept, "disability" — with the quotation marks at least implied-has become the focus of the interdisciplinary field of disability studies. Indeed, if I had to summarize the influence of disability studies as an interdisciplinary field of research and scholarship, I might argue simply that it put quotation marks around "disability." The academic challenge is not just the study of disability, but the study of "disability." What the definitional clauses of the ADA confirm in theory if not in practice is that "disability" has a history as well as a present and a future. It is grounded in experience, but that experience always takes place in a specific context, a time and a place. Understanding that context is how I understand the goal of disability studies. What I want to do here is discuss the meaning of "disability" both as concept and experience.

This is not, by the way, simply a rehearsal of the now familiar distinction between the physical reality of impairment with a layer of social construction added on as

\section{FOCUS ON EXCEPTIONAL CHILDREN}

ISSN 0015-511X

FOCUS ON EXCEPTIONAL CHILDREN is an online, open access journal. Articles are solicited by the Editorial Board and published after review by the Editorial Board. All articles in Focus on Exceptional Children are made available under a Creative Commons Attribution Non-Commercial-NoDerivatives (CC-BY-NC-ND) license and can be found at $\underline{\text { https://journals.ku.edu/focusXchild }}$

\section{Copyright (C) 2019, Focus on Exceptional Children}

Editor: Elizabeth B. Kozleski

Editorial Board: Jamie Basham, Greg Cheatham, Eva Horn, Elizabeth Kozleski, Jose Martinez, Ed Meyen, Tom Skrtic

Technical Support: Marianne Reed disability. The distinction itself is part of the evolution in the concept of "disability" and as such can often use quotation marks itself. "Impairment" is to impairment what "disability" is to disability. The meaning and experience of the concept of "impairment" has its own history and its own future, and as such is part of the problematizing agenda of disability studies. Impairment is just as much a part of a social construct and experiential history as disability itself. The quotation marks are, at some point, unavoidable.

The main argument made here is where I think the field of disability studies might be going: or in other words, what is the future of "disability." However, to provide a context for that discussion, I will first review the history of "disability" - at least in a few very broad strokes. Second, I want to spend a bit more time on the present. Where are we now in our understanding and experience of "disability"? How has the analysis of disablism started to shift to include an equally intensive study of ableism? How has intersectionality led disability studies scholars to call for more integrative exploration of cultural signifiers like race, class, and gender? How have families and the family experiences of "disability" evolved in reaction to disability studies scholarship? Following a consideration of the past and the present, then I want to conclude by discussing some possible directions for the future of the concept of "disability."

\section{THE HISTORICIZING OF "DISABILITY"}

The history of disability studies is much shorter than the history of disability itself. The study of disability extends as far as recorded history can take us. It was always something that needed to be explained. The history of the concept of "disability" is certainly just as long. In a very real sense the history of the concept is necessarily as long as the history of disability itself. The sense always accompanies the reference; the connotation always accompanies the denotation. What seems more recent is the self-reflective study of usage of the term. The history of "disability" is much shorter. In some ways the historiography of "disability" is the history of disability studies, which in turn runs parallel to the history of the disability rights movement. So the history of the concept of "disability" is not a history of disability.

It is certainly true that the academic study of "disability" as a concept finds its beginnings largely in the last few decades of the $20^{\text {th }}$ century. However, even before this formal emergence of a disability studies perspective, there is a thin, but detectable, line of examples where people concerned with - and affected by - the so- 
cial perception of disability discuss the sources and solutions to that issue. At the beginning of the $20^{\text {th }}$ century, there were numerous professionals who acknowledged that the terms of classification that were being used to identify children or adults as "feeble-minded" were often stigmatizing and pejorative. Many of them recognized the power of labeling individuals with the standard terms of classification. In St. Louis, the first separate special education programs for "backward" children were begun in 1908. The first three of these separate schools were given the official title of "Special Schools for Individual Training." As the Superintendent at the time explained, such a name "indicates their purpose and avoids the stigma which the name "Schools for Defectives" would carry" (St. Louis Public Schools, 1905/6, p. 208; Ferguson, 2014). One way around the anticipated resistance of parents and children to placement in a program for "defective" children was to change the terminology, thus reshaping the social construction. In 1914, Elizabeth Farrell (the director of the first special education programs in New York City and one of the founders of the Council for Exceptional Children) put the argument for euphemism plainly:

The present method [of labeling children as merely "backward" and putting them in ungraded classes] has its advantages in that there is less opposition to the segregation of feebleminded children where all are classed as backward than there would be if these unfortunate children were placed in a room known to be maintained for the express purpose of caring for mentally defective children. (Cited in Ferguson, 2014, p. 12)

I would even argue that one could cite Goddard's elaborate mythology for the woman he named "Deborah Kallikak" (her real name was Emma Wolverton) as an at least partially self-aware attempt to harshen the concept of disability used to justify her incarceration (Smith \& Wehmeyer, 2012). Moving in either direction of euphemism or insult is an implicit acknowledgment that the concept involved is malleable; something created or endorsed, rather than discovered. The beginning of a social model is to acknowledge the importance of language in shaping the concepts we use.

By the late 1950s a few more explicit examples of questioning aspects of "disability" as a concept start to appear. In a series of articles in the 50 s and early $60 \mathrm{~s}$, the sociologist Lewis Dexter $(1956,1958,1960,1962)$ called for research on the "problem of mental subnormality" to challenge the dominance of the purely psychological approaches traditionally given sway over definitions of intellectual disability specifically. In an article published in the American Journal of Mental Deficiency (and using the terminology of the era), Dexter explicitly brought up the implications of a more "sociological" approach to the concept:

[M] ental retardation may, in large measure, be a social role, acquired as a result of experience, by highgrade retardates, who have been assigned certain statuses as a result of manifest psycho-biological characteristics. And the major characteristics of the role may have as little necessary relationship to the psycho-biological base as, for example, the Victorian conception of "woman" had to actual differences between the male and the female of Homo Sapiens. (Dexter, 1960, p. 838, italics in original)

In an even earlier article from the same journal (not known for its radical notions of social relativism) a call for definitional diversity was even more explicit:

[B] ecause of the diversity of problems and, consequently, the diversity of modes of description in the area of mental deficiency, it would make good sense for each individual discipline to define mental deficiency and the working constructs related to it in a way which is both clear and useful within the discipline's particular mode of description. (Cantor \& Cromwell, 1957, p. 466)

By the late 1960s, the notion of the social construction of concepts was gaining academic prominence in the social sciences. The challenge to a purely clinical perspective can be found in the emergence or expansion of sociological schools of thought such as symbolic interactionism, and labeling theory associated with names such as Howard Becker (1963), Erving Goffman (1963), and Thomas Scheff (1966). In philosophy, Foucault was beginning his postmodern examination of how power and knowledge were intertwined together in the construction of clinical discourse (Foucault, 1961/2006). In Britain and America, philosophy took a "linguistic turn" (Rorty, 1967) and focused more than ever on how words were not so much a mirror of nature as a forge of meaning (Wittgenstein, 1953/1973), simultaneously shaping connotation as well as reflecting it. It was a time of epistemological and social upheaval that quickly began to challenge assumptions in clinical fields related to disability. This story has been ably summarized elsewhere (Taylor, 2006). For our purposes, it is simply to be noted that long "before it had a name" (Taylor, 2006) disability studiesas the nonclinical focus on the uses and meanings of the concept of disability - was emerging. That history can and should be preserved and deepened. 
Since the 1970s, the attention to "disability" as a concept has grown along side the rise of the disability rights movement and other identity-based scholarship fields such as gender studies and ethnic studies. Disability Studies itself, can be said to have semi-officially gained its name in 1982 with the first meeting of what would become the Society for Disability Studies (Ferguson \& Nusbaum, 2012). Since then, the field has become large enough to have developed numerous subfields in history (Kudlick, 2003), literature (Finger, 2009), cultural studies (Mitchell \& Snyder, 2000), and, of course, education (Skrtic, 1991). As of November 2016, the most reliable compilation identifies some 42 undergraduate, masters, or doctoral programs in disability studies at colleges and universities in the U. S. and Canada (Zubal-Ruggieri, 2016). These are joined by an uncounted number of minors, emphasis areas and concentrations in academic settings of all types.

Even though I argued earlier that his creation of the Kallikak mythology was a pejorative example of manipulating the concept of disability, it is difficult to imagine what sense H. H. Goddard (or any of his contemporaries) would make of disability studies, or anyone talking about the concept of "disability" as reflecting a social model. Indeed, one can find numerous and vocal critics of the field today (e.g., Anastasiou \& Kauffman, 2011). The field itself, while still broadly sharing a general orientation to the nonclinical study of the meaning and experience of disability at both the cultural and personal level, has become somewhat diffuse and messy (Ferguson \& Nusbaum, 2012). Still, the emergence of the concept of "disability" is one that has gained enough academic legitimacy that its present status and future promise seem undeniable. Indeed, the historian Douglas Baynton has argued that understanding this concept and its applications throughout the past is essential to any broader understanding of institutionalized discrimination against devalued and marginalized groups in general:

Disability has functioned historically to justify inequality for disabled people themselves, but it has also done so for women and minority groups. That is, not only has it been considered justifiable to treat disabled people unequally, but the concept of disability has been used to justify discrimination against other groups by attributing disability to them. (Baynton, 2001, p. 33, emphasis in original)

\section{THE PRESENT OF "DISABILITY": TENSIONS AND DEBATES}

As suggested earlier, with the growth of disability studies over the last three or four decades has come some inevitable diffusion of message as well. As scholars have brought the lens of "disability" to various disciplines, the focus has broadened as well. Still I think the field is not yet so large as to be impossible to summarize. Indeed, there are now numerous handbooks and readers (e.g., Davis, 2013; Watson, Roulstone, \& Thomas, 2012) that attempt to do just that. Out of all of this diverse scholarship, the description of disability studies adopted by the Society for Disability Studies comes perhaps as close as anything to an "official" definition of this still relatively new, interdisciplinary field of study:

Disability Studies is [c]hallenging the view of dis-
ability as an individual deficit or defect that can be
remedied solely through medical intervention or re-
habilitation by "experts" and other service provid-
ers. Rather, a program in Disability Studies should
explore models and theories that examine social,
political, cultural, and economic factors that define
disability and help determine personal and collective
responses to difference. At the same time, Disabili-
ty Studies should work to de-stigmatize disease, ill-
ness, and impairment, including those that cannot be
measured or explained by biological science. Finally,
while acknowledging that medical research and in-
tervention can be useful, Disability Studies should
interrogate the connections between medical practice
and stigmatizing disability. (Society for Disability
Studies, n. d.)

What I want to do in this context is less to summarize the present state of disability studies, than it is to highlight some of the current tensions and debates. What are some current themes that are capturing the attention of disability scholars? How has the study of "disability" evolved since the 1980s? I will discuss four themes or issues that I think the field is currently exploring: complicating the social model; disability and difference; tensions between families and disability activists; and considering the implications and obligations of intersectional analysis in the context of "severe" intellectual disability.

\section{Complicating the Social Model}

One way of thinking about the current status of disability studies and the concept of "disability" is as a refusal to take yes for an answer. Regardless of how one parses out the specific meanings of the terms, reference to the "social model" and the "medical model" is commonplace. The terms have become short-hand, umbrella terms to refer to larger discussions of issues of categorization, intervention, and analysis. Indeed, I would argue that most people involved with disability issues would endorse at least a limited version of the so-called social 
model where impairment is reserved for reference to an individual's physical or mental difference and disability is used in a broader sense to cover the external context of policies, programs and attitudes that interact with the impairment in daily life. This is the approach that the World Health Organization has taken in the last decade, using what it calls a "bio-psycho-social" model to try and argue that the medical and social models do not have to be seen as incompatible.

Disability is the umbrella term for impairments, activity limitations and participation restrictions, referring to the negative aspects of the interaction between an individual (with a health condition) and that individual's contextual factors (environmental and personal factors). (World Health Organization and World Bank, 2011, p. 4)

One can argue, as does Jerome Bickenbach (2013), that the WHO definition, through its application as basis of the International Classification of Functioning, Disability and Health (ICF), should be accepted by disability studies scholars who appreciate that different definitions of disability might be used to accomplish different purposes as long as some basic principles are observed.

As an epidemiological tool [the ICF] structures data collection about disability in a manner that fully acknowledges, and operationalizes, the revolutionary kernel of truth that has always been at the core of the social model, namely that disability is the outcome of an interaction between features of the person and features of the person's physical, human-build, attitudinal and social environment. (Bickenbach, 2013, p. 59)

However, many disability studies scholars as well as disability activists would reply that this effort at compromise still does not go far enough. In particular, the reference to disability as still "referring to the negative aspects" of interactions between impairment and society seems to remove the possibility of celebrating disability as a positive signifier of human differences. Goodley (2014) exemplifies this response by positioning "disability" as

A potentiality: a moment, an event, a calling and an encounter. Disability is also a signifier: a term that calls out for signifieds or meanings to be attached. Too often the sign of "disability-pathology" dominates our thoughts. Less well known are, for example, "disability-celebration," "disability-subversion," "disability-desire." These productive signs of disability demand our attention. (p. xi)
In recent years, this position has often expanded into an impatience with the talk about the "social model" itself, at least as commonly understood. Some have argued, following Goodley, that there is a need to find a more wholistic model that captures the full range of disability experiences. Others have policy concerns. The disability law scholar, Sam Bagenstos argues that the social model is too loose and pliable for effective protections in laws such as the ADA. Again, he focuses on the social model's emphasis on the exclusively negative portrayals of living with a disability:

Disability identity is too multifarious, society's re-
sponses to conditions identified as disabilities too di-
verse, for the notion of a societally created category
to offer much traction. . . The more integrated a per-
son with an impairment is in the community, and the
less she conforms with a stereotypical disabled role,
the less likely she is to obtain the ADA's protections.
(Bagenstos, 2009, pp. 50-51)

Whether from a legal or a cultural perspective, there is a well-developed move to push beyond the social/medical model dichotomy. However, the push is not to seek some middle ground of compromise, but rather to reject the pairing altogether. As some have argued, the impairment/disability association seems to implicitly accept the availability of an objective impairment for review and discussion, with disability left as a cloak of connotation that can be taken on or off depending upon the context. The impairment is left then as the "truer" of the two labels; the more basic and enduring reality. However, the consistent constructivist would argue that both concepts - "impairment" and "disability" are inevitably imbued with connotation. Meaning is brought to both terms in a social context depending on what we choose to do with the language we use. Words are tools and can be used to do many different things. The problem is to avoid seeing everyone as a nail, using our preferred words to hammer into submission those who disagree with our purpose.

\section{"Disability" and Difference}

As the concept of "disability" has evolved, so have the responses to the use of that label. One of those responses by some of those traditionally viewed as part of the disability community has been to reject the label altogether. This argument has probably gained the most traction within the D/deaf community (Padden \& Humphries, 2005; Scully, 2012). However, it has also become common among autism advocates and other groups identifying as neurodiverse rather than disabled. In some cas- 
es, this challenge to the label of disability is largely a political strategy adopted to counter what is perceived as the oppressive stigma attached to the disability label. However, increasingly it seems that the notion of disability identity itself is being rejected in a conceptual assault on the narrowness of normality. These arguments usually take the stand that the social construction of disability implies impairment or deficit of the individual. This alternative view, for example, sees deafness:

As a normal human variation - not a failure of function, but a state of being, supported by a distinct culture that currently is not accommodated within mainstream society ... Those who hold this view are saying that the kind of barriers they face are simply not analogous to the ones encountered by other disabled people (that is, hearing people with other kinds of impairment). The major barrier of language difference divides them from other disabled people as much from the non-disabled, hearing majority. (Scully, 2012, p. 115, emphasis in original)

In some ways, of course, this is identity politics at its fractious best. Historically, as the historian Douglas Baynton, among others, has documented, past activists from many oppressed groups have rejected the labels of impairment and disability used to justify their exclusion and marginalization by challenging its application to themselves while implicitly accepting the concept itself.

[D]isability figured prominently not just in arguments for the inequality of women and minorities but also in arguments against those inequalities. Such arguments took the form of vigorous denials that the groups in question actually had these disabilities; they were not disabled, the argument went, and therefore were not proper subjects of discrimination. Rarely have oppressed groups denied that disability is an adequate justification for social and political inequality. (Baynton, 2001, p. 34)

Still today, we hear discussions about the nature and extent of racial disproportionality in special education placement that legitimately focus on the relevance of racism to unjustified labelling and segregation in our schools while risking the unintentional endorsement of the "disability" construct itself.

Perhaps it is possible to acknowledge the pragmatic disadvantages of the disability label while still arguing for a continued crusade to recast the concept to include more positive themes. The poet Richard Wilbur, in an essay where he defended his style of poetry (it usually rhymed) reflected on the overlooked benefits of allowing oneself to be constrained by circumstances: "Limitation makes for power. The strength of the genie comes of his being confined in a bottle" (Wilbur, 1950, p. 7). I am not sure why Wilbur thought of genies as exclusively male, but his point seems useful. If disability theorists and activists alike act from within the constraints of the disability label, they have the power to change the rules of confinement imposed upon them.

\section{Tensions between families and disability advocates}

A third area of contention that bubbles to the surface in disability studies involves the discussion of the long-standing tensions between families of disabled individuals and disability advocates and scholars themselves. Many of these tensions are simply variations of the disability/difference debate. Often nondisabled themselves, parents are viewed as perhaps loving their child but rejecting the disability. The critique is made of mothers who are seen as unfairly denying their children the right to develop an authentic disability identity. Parents themselves often talk of a complicated relationship with a disability community that seems to celebrate the very conditions the parents want to remove or remediate.

\footnotetext{
Mothers of disabled children have occupied a complex, contradictory and marginal position within both disability studies and the disabled people's movement. This marginalization is related to the (often) non-disabled status of the mothers which propels them into the difficult and contentious debates about the role of non-disabled people within disability studies. This tension is further complicated by the relationship between the mothers and their children in which the actions of mothers have been interpreted as constraints within their children's lives, limiting their opportunities and aspirations. (Ryan \& Runswick-Cole, 2008, p. 199)
}

Just as the status of parental advocacy has been newly problematized, so has the social model itself been actively discussed in much of the family literature. On one level, the very mention of the "social model" is, in and of itself, evidence of the influence that disability studies concepts and terminology has had on families and family researchers. It is no longer unusual to see references by families to the social model or social approach (e.g. Lanier, 2014). What is even more indicative of the influence is that, just as in disability studies generally, family research has begun to explore the nuances and variations in how that social model is understood and used by families.

Across several articles and a book length report, Gail Landsman $(1999 ; 2005 ; 2009)$ details the stories of 60 mothers, some of whom were followed over several 
years, whose children were medically diagnosed with a disability. Landsman describes the mothers in her study as caught between the poles of medical and social approaches to disability (although they would have used different terms for their dilemma). On the one hand she found her parents to be generally accepting of the medical approach - even if, as many did, they contested this or that specific diagnosis. On the other hand, she found her parents increasingly convinced of the importance of how their child was perceived by others.

$[\mathrm{M}]$ others are accepting the medical model's authority to define disability as a deficit or defect of the individual yet, at the same time, revealing a belief in a disablement process, a fledgling recognition that disability may not only be about bodies but about attitudes and politics as well. Positioned between medicine and disability rights, most mothers simply sought to do the best for their child; in doing so, they combined their awareness of both to retool the social model. (Landsman, 2005, p. 134)

In a similar vein, Rachel Adams ends her memoir about the first three years of "Raising Henry" (Adams, 2013), her son with Down syndrome, by describing how her personal experience reflected her reaction to the different models of disability that she had come to understand. She sees the models as polar extremes, with science on one end "trying to correct the deficiencies and limitations of people with Down syndrome." On the other end is the disability studies pole, emphasizing "the social environment, rather than the flaws or inadequacies in the individual." She then locates her own interpretation somewhere in the middle:

As I've watched Henry grow up, I've come to believe that his disability lies somewhere in between the two poles. He is certainly more successful in environments that accommodate many different ways of learning and behaving, but there is no environmental change that can erase his disability, which also has to do with the differences of mind and body. That said, if Henry were offered a drug that could help him to better learn and adapt, would I take it? There is no easy answer to that question. ... If a drug to improve cognition made Henry stop being Henry in some fundamental way, then the answer is no. (Adams, 2013, p. 249)

The evidence is clear that parents are starting to put quotation marks around the term "disability." Core concepts and arguments of disability studies have had a noticeable influence on both the research and discourse about families and disability. Direct influence can be seen in the vocabulary of "social model" and "parental voice." However, most of the influence seems implicit and inchoate. The Disability Studies perspective is just beginning to find its way into parent written memoirs and other family narratives. The tension between disability advocates and family members still bubbles beneath the surface. We are left with a situation that seems in flux, but that is suffused with a sense that professionals and parents alike share a sense that the clearest message of all about the concepts of "disability" and "difference" in the family context is: "It's complicated."

\section{Severe Intellectual Disability and Intersectional Analysis}

One of the open secrets of the early years of the disability rights movement and the emerging scholarship of disability studies was its often obvious discomfort with sharing the disability label with the so-called "mentally retarded" population. Just as with the internationally recognized graphical symbol for "disability" (the stick figure in a wheelchair), some of the most prominent spokespersons for independent living (DeJong, 1984) placed physical disability and disability in a synecdochical relationship where the part could be used as a proxy for the whole, with confidence that the intended meaning would not be lost. So, in both terminology and practice, the independent living movement often made physical disability synonymous with disability itself. Intellectual disability, especially severe ${ }^{4}$ intellectual and multiple disability, was implicitly located at the bottom of "disability pecking order" that left discrimination of some unchallenged just as it demanded justice for others. As Erevelles has described the situation:

[E]ven though scholars in the interdisciplinary area of disability studies have (re)theorized disability as a social construction ..., these (re)theorizations continue to leave persons with cognitive/severe disabilities "out in the cold," as if to mark their biology as existing outside all modes of socialization. (Erevelles, 2011, p. 148)

In recent years, the situation has greatly improved. As the second and third waves of disability studies scholars have refined their theoretical approaches a renewed appreciation for the material reality of disability has developed. As I have argued, the simplistic binary of "disability" on the one hand, and "impairment" on the other is increasingly challenged. Analogous in many ways to earlier developments in gender studies, disability studies scholars are trying to "bring the body back in." This in turn has created room for renewed attention to a greater 
range of disabilities, including those of intellectual disabilities (Carlson, 2010; Rapley, 2004). This expansion of scope has not yet, for the most part, made it into the intersectional research that is quickly gaining steam within disability studies currently. However, it would clearly fit with what McCall has referred to as "intra-categorical" complexity in one important strand of intersectional methodology (McCall, 2005). ${ }^{5}$ Just as studying the concept and experience of "disability" in intersection with other signifiers of difference such as race, class, and gender enlarge our understanding of both disability and these identities, so can the study of the concept and experience of severe disabilities enlarge and deepen our understanding of disability in general.

So, why should intersectionality research pay much, if any, attention to this small subset of the disabled population: those with the most significant intellectual and developmental impairments? If, until recently, disability studies has taken little notice in its discussions of race and disability of this segment of the population, why should that change other than perhaps for some notion of thoroughness? The reasons for the absence of this group from the discussion might well be viewed as straightforward. Our understanding of how markers of social difference interact with each other is most usefully developed by studying those situations where cultural procedures and outcomes are most obviously up for debate. Such debate seems unneeded if not inappropriate for children and adults with the most significant disabilities, of whatever race, whatever gender. If one takes a relational approach to constructing meaning around disability, then I believe that both the concept and the daily reality of severe intellectual disability can help refine and sharpen the discourse of intersectionality. In some ways, the power of intersectional analyses emerges most clearly when focused on what might be called an "extreme" example of pathology. If intersectionality can help us understand people with the most severe disabilities then the importance of this emerging discourse is increased by just that much. However, if the concept of severe intellectual disabilities can also help us understand how cultural intersections work in theory and practice, then the robustness of intersectionality as an over-arching frame of analysis is also expanded.

There is no "loyalty oath" for those scholars who find their intellectual home in the interdisciplinary field of disability studies. It is an appropriately messy field of interdisciplinary agendas and methodologies. However, within this scholarly messiness, there are key themes or frameworks for analysis that are commonly held by those who claim to approach their research from this orienta- tion. One of these is a broadly anti-essentialist contention that disability is relational in content, not individual. Disability, in this regard, is thought to be no different from every other category that we use to tell ourselves and others who we are. Indeed, one of the reasons that disability studies scholars are increasingly attracted to the notion of intersectional analysis is that it allows them to build on this anti-essentialist strategy. As Artiles (2013) has argued, intersectionality confronts the reductionist logic used in traditional analyses, and aspires to engage with the simultaneous influence of race, gender, social class, and other forms of difference, as well as the complexities associated with such experiences. In doing that, it "challenges essentialist views of groups, single-axis analyses, and additive models of identity" (Artiles, 2013, p. 336).

All that identifies us as the same and as different is suspended in the webs of social relationships that construct our culture. Disability, then, in a very real sense, resides between us, among us, not inside any one of us. It emerges in our affiliations with each other, our celebrations of differences, our struggles for equality. The fewer of those connections an individual has, then the more disabled he or she becomes. Isolating people with the most significant disabilities serves to make them more disabled, not less, by weakening or preventing those cultural intersections that ultimately rely on comparative experiences of difference.

Unlike with other disabilities, then, severe, multiple disabilities may illustrate a constructive use of intersectionality, where little enculturation had been obvious before. The process of isolating people with the most severe disabilities is based on a discourse of supposedly pre-cultural status. Here we have people who are seen as pre-linguistic, pre-moral, pre-cultural. Their impairment is thought to overwhelm and displace their sexuality, their ethnicity, their age. It comes close to overwhelming their very humanness. From that point of view, the disability of this group of people is the absence of culture, not its distortion. Intersectionality offers a conceptual approach to frame those relationships as critical to understanding each other, including those whose cultural relationships seem most precarious. Displaying the intersectionality of people with the most significant disabilities challenges the assumptions that biology is destiny.

\section{THE FUTURE OF "DISABILITY:" WHERE NEXT FOR DISABILITY STUDIES?}

Over the past four decades or so, the study of disability has expanded into all areas of the academy. From its traditional base in professional fields such as special education and rehabilitation sciences, the study of disabil- 
ity can now be found throughout the social sciences and humanities. Of course, I have argued here that it is really "disability" that is being studied as much as any fixed, objective referent. Theories of disability have become theories of "disability." The process of the enculturation of the notion of "disability" has unavoidably created numerous tensions and disagreements within Disability Studies. Given this relatively short history and contentious but lively present status, what might the future of Disability Studies look like?

As with the previous section and the discussion of the present tensions within Disability Studies, this final section on the future of the field does not in any way claim to be a comprehensive prediction. Rather, I would call it a "curated" collection of a few key themes that I hope the field develops more fully in the coming decade. I will briefly look at three themes: the relevance of Disability Studies to the ongoing issues of policy and practice for disabled people and their families; the fluidity of "disability" and a move to "ability" studies; and the future of the past in the growth of disability history.

\section{Disability Studies, Policy, and Practice}

Many Disability Studies scholars ply their trade within disciplines and professional schools (e.g., education, psychology, human development) where disability has traditionally been framed as a problem to be solved. I would wager that almost all of them have had the experience that I have had of being challenged by students in my classes to make whatever topic I am speaking on be of more use, more practical application. "What does the study of social theory in disability have to do with how to improve teaching and learning in schools of students with disabilities?" It is a predictable question, and not entirely unfair. Even in the humanities, there is a need for a periodic reality check. Disability desperately needs further theorizing. However, the abstractions must never lose touch with daily life. As Wittgenstein framed it, the "slippery ice" of pure theory and logic may be free of friction but dangerous to walk on. To make real progress, we must, sooner or later, go "back to the rough ground" of practice (Wittgenstein, 1973, Part 1, 107, p. 46e).

Of course, with disability policy and practice, the ground may be rougher than Wittgenstein wanted. The policy debates of the next decade may seem depressingly similar to what they were over 40 years ago. Inclusive practices often seem stalled if not under attack. While 14 states now have closed all of their large, public institutions for people with intellectual and developmental disabilities (Larson, et al., 2017), that means over two thirds of states still have over 20,000 individuals incarcerated (almost 40,000 if large, private facilities are included). The Americans with Disability Act seems to be under constant attack to weaken or repeal it entirely. What can Disability Studies have to say at this crucial level of implanting policies that truly challenge the social inequities and marginalization that persist for the disability community in school (Danforth, 2014; Valle \& Connor, 2011) and society?

For me, this is where the experiential side of Disability Studies can have particular relevance. Just as "disability" connotes a contextualized approach to the concept of disability, so might "impairment" connote a way to bring the personal experience of impairment into a contextualized perspective. Through personal memoirs, blogs, and other media, Disability Studies encourages a grounding in reality where pain must be considered real; where skin breakdown is taken seriously; where the frustrations of sensory overload are recognized; where problems of poverty, race, gender and age are experienced with personalized immediacy, not the distance of abstraction. Life story research and pedagogy (Ferri, 2008; 2011; Atkinson, Jackson, \& Walmsley, 2003) can be an effective way to influence the policy narrative and provide a translation of the more abstract conversation that often characterizes the literature in Disability Studies.

Of course, the problem with needed reforms in policy and practice is not only a problem in the United States or the global north generally. The challenge is also very real for disabled people in countries of the global south. One of the issues with disability studies scholarship is that, at least until recently, it often seemed pre-occupied with what is sometimes described as "first world problems." Can the debate about the relationship between concepts of "impairment" and "disability" be meaningfully relevant in situations where basic medical care and education are often absent or costly? How do we discuss theories of inclusion when schooling of any kind is unavailable to children with and without disabilities? The call for intersectional research in Disability Studies must also be a truly international outreach that moves our analyses out of their privileged formulations and neoliberal frameworks (Goodley, 2014). It was supposedly the poet Yeats who somewhere commented that he "liked a little seaweed in his definition of water." Regardless of who said it, the observation conveys the need for our scholarly debates not to be distilled into such purely intellectual arguments that they lose the messiness of the real world; the impurities of daily life that complicate our logic. We must keep the cultural seaweed in our definitions of disability. 
The Fluidity of "Disability" and the Study of Normality Just as feminist studies has problematized the concept of "maleness," and Critical Race Theory has challenged traditional notions of "whiteness," so has Disability Studies begun to focus on the master category of "normality" and how it shapes our understanding of disability. My sense is that, in the coming decade, the domination of "normality" will be challenged in an intersectional approach to identity that has already problematized the norms of whiteness and maleness. As the disability studies scholar, Lennard Davis has put it:

Is it possible that normal, in its largest sense, which has done such heavy lifting in the area of eugenics, scientific racism, ableism, gender bias, homophobia, and so on, is playing itself out and losing its utility as a driving force in culture in general and academic culture in particular? ... Another way of putting this point, somewhat tautologically, is that diversity is the new normality. (Davis, 2013, p. 1)

One wonders if the future of disability studies will be under the banner of "ability studies" or perhaps "diversity studies." At least one scholar (Goodley, 2014) has already invoked the favorite postmodern use of the slash to produce "dis/ability studies" as a way of conveying the equal emphasis on both concepts of "disability" and "ability." As we increasingly challenge the norms of normality, then cultural space opens up for "disability as a problem" to transform into "disability as a way of being in the world." It would, as Rosemary Garland Thompson has put it, go about "building a world with disability in it" (Garland-Thompson, 2017, p. 51) rather than striving for one where disability is removed.

In sum, the cultural model of disability implies a fundamental change of epistemological perspective since it does not deal with the margin but rather with the "centre" of society and culture ... [O]ne should no longer problematize just the category of disability, but rather the interplay between "normality" and "disability." (Waldschmidt, 2017, pp. 25-26)

One of the challenges facing this problematizing normativity is the language we rely on. In our usage, the term "ability" is often meant as the opposite of the term "disability." You either have ability or you have a disability. To be normal becomes separated from the ability-disability continuum, to become a master signifier, functioning in the same way that heterosexuality and whiteness become cover terms. Normal is the default status, when diversity is the reality. One terminological possibility to capture this fluidity would be to coin a term that, in the spirit of intersectionality, borrows on usages from other areas of identity studies. So, gender studies over the last 20 years or so, the term "cisgender" has gained usage as the opposite of "transgender." A cisgendered person, according to the OED denotes someone whose self-identity conforms with the gender that corresponds to their biological sex" (cited in Brydum, 2015). Both cisgender and transgender draw on their Latin roots, with "trans" meaning "across" or "on the other side of," while "cis" means "on this side of" (Brydum, 2015). So, a cis-abled person would be someone whose self-identity conforms with the ability levels considered culturally normative. A cisabled person is the opposite of a disabled person in the way that a cisgendered person differs from a transgendered person. Ability studies would then be the study of cisabled and disabled people with attention to the personal and cultural processes by which that assignment gets determined.

Whether or not that catches on, the point is that the fluidity of "disability" and "ability" are mutually dependent concepts, embedded in cultural spaces and times. This whole challenge to normality as a status seems likely to be the starting point, rather than the conclusion, for much of the next decade's writing in what is now called "disability studies."

\section{The Future of the Past and the Growth of Disability History}

My last theme for the future is more of a hope than a prediction. My hope is that the emergence of critical disability history (or history from a disability studies orientation) continues to grow in both quality and quantity. I want there to be a lot of the past in the future of Disability Studies. To study the history of something is to try and discover how it has changed over time. The history of the concept and experience of disability shows how that change has followed certain patterns. To historicize "disability" is to ground the concept in the fluctuations of culture and experience in ways that bolster the current attempts to analyze "disability" through a contemporary cultural lens. As others have noted, history may not repeat itself, but it often rhymes. ${ }^{6}$ The history of disability, as well as the history of "disability" helps us discover the relevance of past arguments to current debates; to look for those historical couplets. Why do we arrange our services for people with disabilities along a continuum, from most segregated to most integrated? Is there a time when this practice began or is just unavoidably logical outcome of responding to human variance of need? We have done well in producing excellent explorations of the emergence and growth of the $19^{\text {th }}$ century asylum. How- 
ever, most people with disabilities, including those with intellectual disabilities, have always lived in the community. We need to understand more about what daily life in the community was like in the past centuries for people with these labels and their families.

However, for me the most attractive historical project for the next decade or two will be the production of cross-disability accounts that compare and contrast historical experiences of people with different disability labels. For the most part, our current historiography of disability consists primarily of intra-categorical studies. So we have histories of Deafness, histories of blindness, of intellectual disability. In the inevitable process of academic specialization, we see more and more narrowly focused studies that provide more and more detail about smaller and smaller groups. This is also a result of many of these histories being written by scholars who come to their topic not through a background in historical research but one in some specialized area of disability services. Whatever the cause, there is much to be gained from comparing experiences across the disability spectrum.

One area of promise would be to look at the concept of "chronicity" (Ferguson, 1994) across disability categories. "Chronicity" is simply the professional categorization of someone as beyond help or cure, perhaps capable of small improvement, but not salvageable for success in the general community. We can see this label clearly in the $19^{\text {th }}$ and $20^{\text {th }}$ century with services to the so-called feeble-minded population, both as children and adults. The importance of the label was two-fold. First it provided a seemingly objective justification for professional failure by attributing to the severity of individual defects rather than inadequacy of professional expertise. Second, however, it allowed a clinical rationale for selective intervention. Attention was to be focused on those who could be helped, with the remainder to be left to the purgatory of custodial neglect. The question is how and whether that process plays out across disability categories. So, instead of a history of severe intellectual disability, or profound hearing loss, or severe physical disability, we need histories of "chronicity" that compare that process of abandonment across diagnoses, and histories.

\section{CONCLUSION}

So, where are we in the study of "disability." Just as the past few decades have seen dramatic changes in the perception of disability and people's experience of it, so have we seen the academic conversation evolve in how we talk and think about "disability" as a concept. That conversation will continue to evolve, but it is difficult to imagine it going back at this point. For me the challenge will be to see an increased dialogue between what is now too often a muted distrust of traditional, clinical approaches and policy critiques and the more culturally based narratives that focus on "disability" as a concept and a personal identity. Each discourse has its place and purpose. The tension between the two will always be at the surface. However, that tension can be dynamic and enlivening rather than disdainful and dismissive.

It is a large and daunting project. However, the size of the task should not be a reason to abandon the effort. The social critic I. F. Stone supposedly once said: "If you expect to see the final results of your work, you simply have not asked a big enough question." That is the approach we should emulate. Ask big questions. Do not expect quick answers or complete ones. Disability Studies makes room for big questions. So should the applied fields of special education and human services. Indeed, the biggest question of all for special education may be how to incorporate the broader understandings of disability that Disability Studies has raised. Perhaps that should be part of the future of "disability." With or without quotation marks.

\section{ENDNOTES}

1. In the House, the final vote for passage was 377 to 28 ; the Senate vote was 91 to 6 in favor. Of course, this final bipartisan outcome was presaged by years of sometimes bitter wrangling over details about who would be covered and how the law would determine compliance. The fascinating backstory is told in a very accessible way by Lennard J. Davis (2015) in his book, Enabling Acts.

2. As with most oppressed or stigmatized groups, disability terminology is somewhat contested. People-first language (a person with a disability) is often preferred by professionals and many families, while identity-first language (a disabled person) is usually the choice of disability studies scholars and many disability activists. I will use both phrasings here, depending on the context.

3. According to the Bureau of Labor Statistics (2017), the rate of unemployment for people with disabilities is reported at $10.5 \%$ for 2016, down from $15 \%$ in 2011. However, that rate is still more than twice the $4.6 \%$ rate for people without disabilities. Moreover, the truly revealing statistic is that only $20 \%$ of people with disabilities even participated in the labor market (compared to $68.5 \%$ of people without disabilities).

4. Terminology here is again contested. Some prefer the term "significant" or "most significant" disabilities to refer to this subset of those labeled as intellectually disabled. The individuals I am referring to usually have little or no language. They usually have labels of "extensive" and "pervasive" intellectual support needs associated with ID, and often have more than one significant impairment.

5. In McCall's analysis, the key premise of this approach within intersectional studies, whether talking about gender, race, or, I would add, disability, is that "a wide range of different experiences, identities, and social locations fail to fit neatly into any single 'master' category" 
(McCall, 2005, p. 1777). With disability studies the "master category" is the abled/disabled binary.

6. There are many versions of this quotation and they are often attributed to Mark Twain. However, this has been challenged, and the exact origin is not easily established. A thorough attempt to find the origin can be found in the useful website: The Quote Investigator (O’Toole, 2014)

\section{REFERENCES}

Adams, R. (2013). Raising Henry: A memoir of motherhood, disability, and discovery. New Haven: Yale University Press.

Anastasiou, D. \& Kauffman, J. M. (2011). A social constructionist approach to disability: Implications for special education. Exceptional Children, 77, 367-384.

Artiles, A. (2013). Untangling the racialization of disabilities: An intersectionality critique across disability models. $\mathrm{Du}$ Bois Review, 10, 329-347.

Atkinson, D., Jackson, M., \& Walmsley, J. (2003). Forgotten lives: Exploring the history of learning disability. Plymouth, UK: British Institute of Learning Disabilities.

Bagenstos, S. R. (2009). Law and the contradictions of the disability rights movement. New Haven, CT: Yale University Press.

Baynton, D. C. (2001). Disability and the justification of inequality in American history. In P. K. Longmore \& L. Umansky (Eds.), The new disability history: American perspectives (pp. 33-57). New York: New York University Press.

Becker, H. (1963). Outsiders: Studies in the sociology of deviance. New York: Free Press.

Bickenbach, J. E. (2013). The international classification of functioning, disability and health and its relationship to disability studies. In N. Watson, A. Roulstone, \& C. Thomas (Eds.), Routledge handbook of disability studies (pp. 51-66). New York: Routledge.

Brydum, S. (January 12, 2015) The true meaning of the word 'cisgender.' The Advocate. Retrieved on February 15, 2018 from www.advocate.com/transgender/2015/07/31/ true-meaning-word-cisgender

Bureau of Labor Statistics, U. S. Department of Labor (2017). Unemployment rate of people with a disability 10.5 percent in 2016, The Economics Daily. Retrieved from the internet on February 1, 2018 at https://www.bls.gov/opub/ ted/2017/unemployment-rate-of-people-with-a-disability10-point-5-percent-in02016.htm

Cantor, G. N., \& Cromwell, R. L. (1957). The principle of reductionism and mental deficiency. American Journal of Mental Deficiency, 61, 461-466.

Carlson, L. (2010). The faces of intellectual disability: Philosophical reflections. Bloomington: Indiana University Press.

Danforth, S. (2014). Becoming a great inclusive educator. New York: Peter Lang.

Davis, L. J. (Ed.) (2013). The disability studies reader ( $4^{\text {th }}$ edition). New York: Routledge.
Davis, L. J. (2013). The end of normal: Identity in a biocultural era. Ann Arbor: University of Michigan Press.

Davis, L. J. (2015). Enabling acts: The hidden story of how the Americans with Disabilities Act gave the largest U.S. minority its rights. Boston, MA: Beacon Press.

DeJong, G. (1984). Independent living: From social movement to analytic paradigm. In R. P. Marinelli \& A. E. Dell Orto (Eds.) The psychological and social impact of the physical disability ( $2^{\text {nd }}$ ed.) (pp. 39-63). New York: Springer.

Dexter, L. A. (1956). Towards a sociology of the mentally defective. American Journal of Mental Deficiency, 61, 10-16.

Dexter, L. A. (1958). A social theory of mental deficiency. American Journal of Mental Deficiency, 62, 920-928.

Dexter, L. A. (1960). Research on the problems of mental subnormality. American Journal of Mental Deficiency, 64, 835-838.

Dexter, L. A. (1962). On the politics and sociology of stupidity. Social Problems, 9, 221-228.

Emens, E. F. (2013). Disabling attitudes: U. S. disability law and the ADA Amendments Act. In L. J. Davis (Ed.), The disability studies reader (4 ${ }^{\text {th }}$ ed.) (pp. 42-57). New York: Routledge.

Erevelles, N. (2011). Disability and difference in global contexts: Enabling a transformative body politic. New York: Palgrave Macmillan.

Ferguson, P. M. (1994). Abandoned to their fate: Social policy and practice toward severely retarded people in America, 1820-1920. Philadelphia, PA: Temple University Press.

Ferguson, P. M. (2014). Creating the continuum: J. E. Wallace Wallin and the role of clinical psychology in the emergence of public school special education in America. International Journal of Inclusive Education, 18 (1), 86100.

Ferguson, P. M., \& Nusbaum, E. (2012). Disability studies: What is it? What difference does it make? Research and Practice for Persons with Severe Disabilities, 37(2), 7080.

Ferri, B. A. (2008). Changing the script: Race and disability in Lynn Manning's Weights. International Journal of Inclusive Education, 12, 497-509.

Ferri, B. A. (2011). Disability life writing and the politics of knowing. Teachers College Record, 113, 2267-2282.

Finger, A. (2009). Call me Ahab: A short story collection. Lincoln: University of Nebraska Press.

Foucault, M. \& Khalfa, J. (Ed.). (2006). The history of madness. (J. Khalfa \& J. Murphy, Trans.). New York: Routledge.

Garland-Thompson, R. (2017). Building a world with disability in it. In A. Waldschmidt, H. Berressem, \& M. Ingwersen (Eds.), Culture-theory-disability: Encounters between disability studies and cultural studies (Vol. 10, pp. 51-62). transcript Verlag.

Goffman, E. (1963). Stigma: Notes on the management of spoiled identity. Englewood Cliffs, NJ: Prentice-Hall.

Goodley, D. (2014). Dis/Ability studies: Theorising disablism and ableism. New York: Routledge. 
Kudlick, C. J. (2003). Disability history: Why we need another "other." American Historical Review, 108, 763-793.

Landsman, G. (1999). Does God give special kids to special parents? Personhood and the child with disabilities as gift and as giver. In L. Layne (Ed.), Transformative motherhood (pp. 133-166). New York: New York University Press.

Landsman, G. (2005). Mothers and models of disability. Journal of Medical Humanities, 26, 121-139.

Landsman, G. H. (2009). Reconstructing motherhood and disability in the age of "perfect" babies. New York: Routledge.

Lanier, H. K. (2014, January 5). Breaking up with Doctor Normal. [Web log post]. Retrieved on February 2, 2018 from http://starinhereye.wordpress.com/2014/01/05/breakingup-with-doctor-normal/

Larson, Sheryl A., Eschenbacher, J. J., Anderson, L. L., Taylor, B., Pettingill, S., Hewitt, A., Sowers, M., \& Bourne, M. L. (2017). In-home and residential long-term supports and services for persons with intellectual or developmental disabilities: Status and trends, 2015. Minneapolis: University of Minnesota, Research and Training Center on Community Living, Institute on Community Integration.

McCall, L. (2005). The complexity of intersectionality. Signs, 30, 1771-1800.

Mitchell, D. T., \& Snyder, S. L. (2000). Narrative prosthesis: Disability and the dependencies of discourse. Ann Arbor: University of Michigan Press.

O'Toole, G. (January 12, 2014). Retrieved from the web on February 12, 2018 at https:/quoteinvestigator. com/2014/01/12/history-rhymes/

Padden, C., \& Humphries, T. (2005). Inside deaf culture. Cambridge, MA: Harvard University Press.

Pelka, F. (2012). What have we done: An oral history of the disability rights movement. Boston: University of Massachusetts Press.

Rapley, M. (2004). The social construction of intellectual disability. New York: Cambridge University Press.

Rorty, R. (1967). The linguistic turn: Essays in philosophical method. Chicago: University of Chicago Press.

Ryan, S., \& Runswick-Cole, K. (2008). Repositioning mothers: Mothers, disabled children and disability studies. Disability \& Society, 23, 199-110.

St. Louis Public Schools (1905/06). 52 $2^{\text {nd }}$ annual report of the board of education for the city of St. Louis. St. Louis, MO: St. Louis Public Schools.
Scheff, T. J. (1966). Being mentally ill: A sociological theory. Chicago: Aldine Publishing Co.

Scully, J. L. (2012). Deaf identities in disability studies: With us or without us? In N. Watson, AA. Roulstone, \& C. Thomas (Eds.), Routledge handbook of disability studies (pp. 109121). New York: Routledge.

Skrtic, T. M. (1991). Behind special education: A critical analysis of professional culture and school organization. Denver: Love Publishing.

Smith, J. D., \& Wehmeyer, M. L. (2012). Good blood; bad blood: Science, nature, and the myth of the Kallikaks. Washington D. C.: American Association on Intellectual and Developmental Disabilities.

Society for Disability Studies (n.d.). What is Disability Studies? Retrieved February 1, 2018 https://disstudies.org/index. php/about-sds/what-is-disability-studies/

Taylor, S. J. (2006). Before it had a name: Exploring the historical roots of disability studies in education. In S. Danforth \& S. L. Gabel (Eds.), Vital questions facing disabilities in education, (pp. xiii-xxiii). New York: Peter Lang.

Valle, J., \& Connor, D. (2011). Rethinking disability: A disability studies approach to inclusive practices. New York: McGraw-Hill.

Waldschmidt, A. (2017). Disability goes cultural: The cultural model of disability as an analytical tool. In A. Waldschmidt, H. Berressem, \& M. Ingwersen (Eds.), Culture-theory-disability: Encounters between disability studies and cultural studies (Vol. 10, pp.19-27). transcript Verlag.

Watson, N., Roulstone, A., \& Thomas, C. (Eds.) (2012). Routledge handbook of disability studies. New York: Routledge.

Wilbur, R. (1950). The genie in the bottle. In J. Ciardi (Ed.), Mid-century American poets (pp. 1-7). New York: Twayne Publishers.

Wittgenstein, L. (1973). Philosophical investigations (3rd ed., G.E.M. Anscombe, Trans.). Upper Saddle River, NJ: Prentice Hall. (Original work published in 1953)

World Health Organization, and the World Bank (2011). World report on disability. Geneva: World Health Organization and The World Bank.

Zubal-Ruggieri, R. (2016). Academic programs in disability studies. http://disabilitystudies.syr.edu/programs-list/ Retrieved from the web on February 1, 2018. 